\title{
openheart Exercise-based cardiac rehabilitation for stable angina: systematic review and meta-analysis
}

\author{
Linda Long, ${ }^{\oplus 1}$ Lindsey Anderson, ${ }^{2}$ jingzhou He, ${ }^{3}$ Manish Gandhi, ${ }^{3}$ Alice Dewhirst, ${ }^{4}$ \\ Charlene Bridges, ${ }^{5}$ Rod Taylor ${ }^{1}$
}

\begin{abstract}
- Additional material is published online only. To view please visit the journal online (http://dx.doi.org/10.1136/ openhrt-2018-000989).
\end{abstract}

To cite: Long L, Anderson L, He jingzhou, et al. Exercisebased cardiac rehabilitation for stable angina: systematic review and meta-analysis. Open Heart 2019;6:e000989. doi:10.1136/ openhrt-2018-000989

Received 13 December 2018 Revised 15 February 2019 Accepted 8 March 2019

\section{Check for updates}

(c) Author(s) (or their employer(s)) 2019. Re-use permitted under CC BY. Published by BMJ.

${ }^{1}$ Institute of Health Research, University of Exeter Medical School, Exeter, UK

${ }^{2}$ Department of Innovation, Impact \& Business, University of Exeter, Exeter, UK

${ }^{3}$ Department of Cardiology, Royal Devon \& Exeter NHS Foundation Trust Hospital, Exeter, UK

${ }^{4}$ University of Exeter Medical School, Exeter, UK

${ }^{5}$ Farr Institute of Health Informatics Research, University College London, London, UK

Correspondence to Dr Linda Long, Institute of Health Research, University of Exeter Medical School, Exeter EX1 2LU, Devon, UK; L.Long@exeter.ac.uk

\section{ABSTRACT}

Objective A systematic review was undertaken to assess the effects of exercise-based cardiac rehabilitation (CR) for patients with stable angina

Methods Databases (Cochrane Central Register of Controlled Trials, MEDLINE, Embase and CINAHL) were searched up to October 2017, without language restriction. Randomised trials comparing CR programmes with no exercise control in adults with stable angina were included. Where possible, study outcomes were pooled using meta-analysis. Grading of Recommendations Assessment, Development and Evaluation was used to assess the quality of evidence. The protocol was published on the Cochrane Database of Systematic Reviews.

Results Seven studies (581 patients), with a median of 12-month follow-up, were included. The effect of exercisebased CR on all-cause mortality (risk ratio (RR) 1.01, 95 $\% \mathrm{Cl}: 0.18$ to 5.67 ), acute myocardial infarction (RR 0.33 , $95 \% \mathrm{Cl}: 0.07$ to 1.63 ) and cardiovascular-related hospital admissions (RR $0.14,95 \% \mathrm{Cl}: 0.02$ to 1.1 ) relative to control were uncertain. We found low-quality evidence that exercise-based $\mathrm{CR}$ results in a moderate improvement in exercise capacity (standard mean difference $0.45,95 \% \mathrm{Cl}$ : 0.20 to 0.70 ). There was limited and very low-quality evidence for the effect of exercise-based CR on healthrelated quality of life (HRQoL), adverse events and costs. No data were identified on cost-effectiveness or return to work.

Conclusions Exercise-based CR may improve the shortterm exercise capacity of patients with stable angina pectoris. Well-designed randomised controlled trials are needed to definitely determine the impact of CR on outcomes including mortality, morbidity, HRQoL, and costs in the population of patients with stable angina receiving contemporary medical therapy.

\section{INTRODUCTION}

With increasing numbers of patients living longer with symptomatic coronary heart disease (CHD), the effectiveness and accessibility of health services for patients with CHD have never been more important. Cardiac rehabilitation (CR) is recognised as integral to the comprehensive care of patients with CHD. ${ }^{1}$ CR is a process by which patients, in partnership with health professionals, are

\section{Key questions}

What is already known about this subject?

- Cardiac rehabilitation (CR) is recognised as integral to the comprehensive care of patients with coronary heart disease. CR is a process by which patients, in partnership with health professionals, are encouraged and supported to achieve and maintain optimal physical health, with exercise training at the centre of rehabilitation provision for $\mathrm{CR}$. There is an absence of evidence and consequently inconsistency in guideline and policy recommendations for the use of CR programme for patients with stable angina. American College of Cardiology/American Heart Association and European Society of Cardiology guidelines recommend $\mathrm{CR}$ for patients with cardiac disease, including patients with stable angina. The 2017 British Association for Cardiovascular Prevention and Rehabilitation guidelines recommend CR for people with established forms of cardiovascular disease, including stable angina. However, the National Institute for Health and Care Excellence do not recommend $\mathrm{CR}$ in their clinical guidelines for the management of stable angina.

What does this study add?

- This systematic review assesses the impact of CR for people with stable angina, defined in this review as chest pain and associated symptoms precipitated by activity (eg, running, walking) with minimal or non-existent symptoms at rest. The review finds exercise-based CR may improve the short-term exercise capacity of people with stable angina pectoris, based on low-quality evidence. The review finds insufficient evidence to determine effectiveness of exercise-based CR on clinical relevant outcomes or quality of life.

encouraged and supported to achieve and maintain optimal physical health. ${ }^{2}$ While physical exercise training is at the centre of rehabilitation provision for CR, it is now accepted that programmes should be comprehensive in nature and also include education and psychological care, as well as focus on health and life-style behaviour change and psychosocial well-being. ${ }^{3}$ 


\section{Key questions}

How might this impact on clinical practice?

- The impact of exercise-based CR for adults with stable angina is uncertain due to insufficient evidence, with the quality of the evidence graded as low to very low. However, it may be associated with a moderate increase in exercise capacity compared with no exercise control. Well-designed randomised controlled trials are required to definitively assess the impact of adding CR to contemporary usual care in terms of mortality, morbidity, health-related quality of life, and costs.

Stable angina is a form of chronic heart disease associated with ill health and increased death rates and is defined in this review as chest pain and associated symptoms precipitated by activity (eg, running, walking) with minimal or non-existent symptoms at rest. It was estimated that in 2013 over 1.3 million people in the UK had angina $^{4}$ and it was thought to affect approximately 112 million people, or $1.6 \%$ of the population worldwide. ${ }^{5}$ Although clinical guidelines consistently recommend referral for CR for post-myocardial infarction (MI) and patients with heart failure (HF), advice for patients with stable angina is less clear. The American College of Cardiology/American Heart Association give a Class I recommendation that medically supervised CR programmes and physician-directed, home-based programme are offered to at-risk patients with stable CHD including those with stable angina, at first diagnosis. ${ }^{6}$ Similarly, the European Society of Cardiology recommends that people with stable CHD, including stable angina, should undergo 'moderate-to-vigorous intensity aerobic exercise training $\geq 3$ times a week and for 30 min per session'. However, National Health and Care Excellence (NICE) guideline for the management of stable angina (CG126) states that there is 'no evidence to suggest that CR is clinically or cost-effective for managing stable angina' ${ }^{8}$

To inform current practice and policy, we therefore sought to undertake a systematic review and meta-analysis of randomised controlled trials (RCTs) to assess the effects of exercise-based CR versus usual care on mortality, morbidity, hospital admissions, exercise capacity, health-related quality of life (HRQoL), adverse events and return to work for adults with stable angina.

\section{METHODS}

We conducted and reported this systematic review in accordance with the Preferred Reporting Items for Systematic Reviews and Meta-Analyses statement and the Cochrane Handbook for Interventional Reviews. ${ }^{9}$ The protocol was published on the Cochrane Database of Systematic Reviews. ${ }^{10}$

\section{Searches}

We adapted the search strategy based on the Cochrane systematic review of exercise-based CR for CHD. ${ }^{11}$ We searched databases using a strategy combining selected
Medical Subject HeadingsMeSH terms and free-text terms relating to exercise-based rehabilitation and stable angina, with filters applied to limit to RCTs. Electronic searches of the Cochrane Central Register of Controlled Trials, MEDLINE, EMBASE and CINAHL plus others (see online supplementary document A) were performed. Databases were searched up to September 2016 with no language or other restrictions, and then updated with a further search up to October 2017. Trial registers ( www.who.int/ictrp/en and clinicaltrials.gov) were also checked, in addition to reference lists of all eligible studies and other published systematic reviews.

\section{Study selection}

We included randomised trials (individual or cluster) directly comparing CR programmes with a no exercise control or usual care comparison. The study population included adults with stable or exertional angina (effort-induced chest discomfort), who were being treated with medical anti-anginal therapy and who may have had a MI, coronary artery bypass graft (CABG) or percutaneous coronary intervention (PCI). We excluded patients in the immediate period following such an event that is, within 3 months of previous MI, CABG or PCI. We also excluded patients with unstable angina (pain at rest) and those with refractory angina for whom revascularisation was planned.

Studies with one or more of the following outcome measures with $\geq 6$ month-follow-up were included: mortality (cardiac and overall); morbidity (reinfarction, revascularisation or cardiac-related hospitalisation); exercise capacity; HRQoL, adverse events (withdrawal from the trial or exercise programme); return to work. Selection of studies involved the initial screening of titles and abstracts, followed by an assessment of the full-text reports of all potentially relevant trials. Two authors (AD and LA) independently assessed trials for inclusion and where there was a disagreement, the opinion of a third author (RST, GH or MG) was sought.

\section{Data extraction and risk of bias assessment}

The following information was extracted: study design, participants (baselinecharacteristics), details of the intervention (including type, frequency, duration and intensity of exercise training and nature of co-interventions), length of follow-up and outcome results. We assessed study risk of bias using the Cochrane standard criteria $^{9}$ (random sequence generation and allocation concealment, dropouts and withdrawals, outcome blinding, and selective reporting) and two further items deemed relevant to this review (balance of groups at baseline and if the study groups received comparable care (apart from the exercise component of the intervention)). These criteria, agreed on in advance by the review authors, have not been validated but have been used to assess quality in previous CR reviews ${ }^{11-15}$

Data extraction and risk of bias assessment were carried out independently by three authors (LL, JH and 


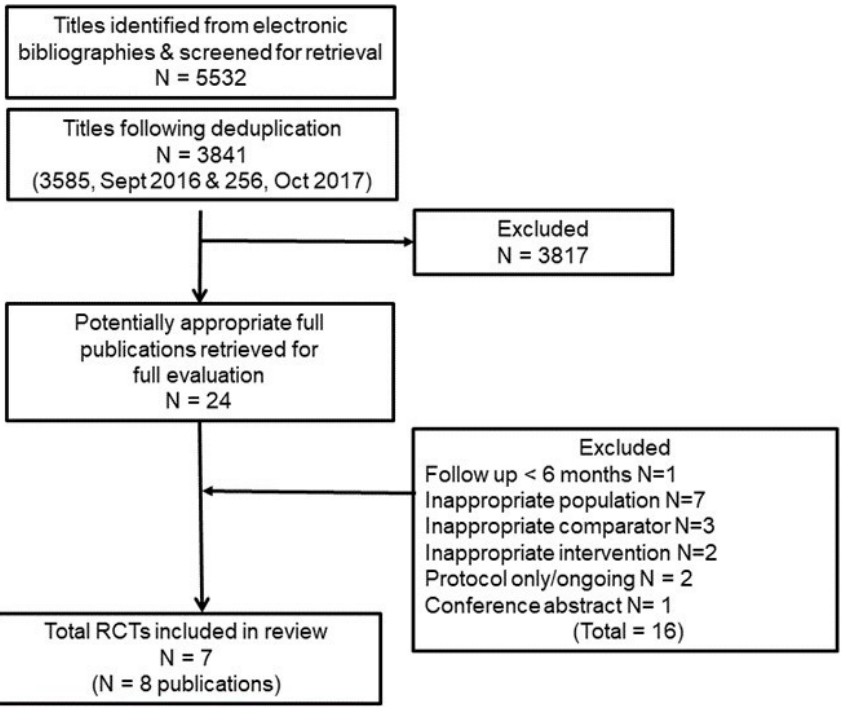

Figure 1 Summary of study selection process. RCT, randomised controlled trials.

$\mathrm{AD})$. Any disagreements were resolved by consensus and decisions were independently checked by a third author (RST). Where necessary, authors of included studies were contacted for further information (eg, when a study was identified as abstract only).

\section{Data analysis}

Data were analysed in accordance with the Cochrane Handbook. ${ }^{9}$ For dichotomous variables, relative risks (RRs) and 95\% CIs were calculated for each outcome, and for continuous variables, mean differences (MDs) and $95 \%$ CIs were calculated. Given the variety of outcome measures reported for exercise capacity, to allow us to pool findings across studies, between-group results for each study were expressed as a standard MD (SMD). Where differences between groups for each individual trial were not reported, we calculated $p$ values for the differences.

We explored heterogeneity among the included studies qualitatively (by comparing the study characteristics) and quantitatively (using the $\chi^{2}$ test of heterogeneity and $\mathrm{I}^{2}$ statistic). Where appropriate, an overall estimate of treatment effect was obtained by combining the results from included studies for each outcome. We employed a random-effects model where there was formal evidence of statistical heterogeneity (ie, $\chi^{2}$ test $p$ value $<0.10$ and $\mathrm{I}^{2}$ statistic of $\left.50 \%-90 \%\right)$. For outcomes with lower levels of statistical heterogeneity, we applied both fixed and random effects models, reporting fixed-effects results unless there was a difference in statistical inference, where we reported the most conservative random-effects model. We sought to explore small-study bias and the potential for publication bias using funnel plot and the Egger test ${ }^{16}$

Analyses were undertake using Review Manager Software V.5.3 (Nordic Cochrane Group, Copenhagen, Denmark).

\section{Summary of findings table}

Two reviewers (LL and RST) independently employed the Grading of Recommendations Assessment, Development and Evaluation (GRADE) approach ${ }^{17}$ to interpret result findings. We used the five GRADE considerations (study limitations, consistency of effect, imprecision, indirectness and publication bias) to assess the quality of a body of evidence from studies that contributed data to the meta-analyses and narrative summaries for the pre-specified outcomes. Any discrepancies in judgements were resolved through discussion. One reviewer (LL) used GRADEpro GDT 2015 to import data from Review Manager to create a 'Summary of findings' table using the following pre-specified outcomes: all-cause mortality; MI; all-cause hospital admissions; HRQoL, return to work and exercise capacity.

\section{RESULTS}

\section{Study selection}

Figure 1 summarises the screening process resulting in eight publications across seven RCTs included in the review.

\section{Characteristics of included studies}

The seven RCTs included a total of 581 patients with stable angina. A summary of study characteristics is shown in tables 1 and 2.

\section{Risk of bias}

Overall risk of bias was judged to be poor, most studies being insufficiently reported to fully assess their potential risk of bias (see figure 2). The reporting of details tended to be poorer in studies published prior to $2000 .^{18-20}$ Details of selection bias (random allocation sequence generation and concealment) and reporting bias were particularly poorly reported. Only two studies stated they took measures to blind outcome assessment. ${ }^{18}{ }^{21}$ Loss to follow-up or dropout as well as whether groups received the same co-interventions appeared to vary considerably across studies. Where reported, losses to follow-up and drop-out were relatively high, ranging from $15 \%$ to $58 \%$ across studies. The majority of trials were judged to be of low risk of bias in terms of the risk associated with groups being unbalanced at baseline.

\section{Impact of CR on outcomes}

\section{Mortality and morbidity}

Three studies $^{19} 2022$ (195 participants) reported a total of four all-cause deaths with a pooled RR of 1.01 (95\% CI: 0.18 to $5.67, \mathrm{I}^{2}=0 \%$, fixed effects). We are uncertain if CR has little or no effect on all-cause mortality due to very low-quality evidence (Summary of findings table 3). One study (Schuler 1992) ${ }^{20}$ reported cardiovascular-related mortality in two participants in the CR group and none in the control.

\section{Morbidity}

Three studies ${ }^{19-21}$ (254 participants) reported on the incidence of MI with a total of six events. There was a 
Table 1 Summary of individual studies

\begin{tabular}{|c|c|c|c|c|c|c|}
\hline Study & $\begin{array}{l}\text { Participants } \\
\text { (number and } \\
\% \text { men) }\end{array}$ & $\begin{array}{l}\text { Intervention, } \\
\text { comparator } \\
\text { and setting }\end{array}$ & Exercise prescripti0m & Outcomes & Follow-up & Country/setting \\
\hline $\begin{array}{l}\text { Devi et al } \\
2014^{23}\end{array}$ & $\begin{array}{l}94 \text { stable angina } \\
\text { pectoris; } 74 \% \\
\text { men }\end{array}$ & $\begin{array}{l}\text { Home-based } \\
\text { online web-based } \\
\text { intervention }\end{array}$ & $\begin{array}{l}\text { Dose: Individualised daily exercise } \\
\text { (most commonly walking) } \\
\text { Length of session: Not reported } \\
\text { Frequency: Daily } \\
\text { Intensity: Moderate } \\
\text { Total duration: } 6 \text { weeks }\end{array}$ & $\begin{array}{l}\text { HRQoL and anxiety and } \\
\text { depression }\end{array}$ & 6 months & UK, single centre \\
\hline $\begin{array}{l}\text { Hambrecht et } \\
\text { al } 2004^{21}\end{array}$ & $\begin{array}{l}101 \text { classes I to III } \\
\text { angina pectoris; } \\
100 \% \text { men }\end{array}$ & $\begin{array}{l}\text { Home-based } \\
\text { aerobic training } \\
\text { (bicycle ergometer) }\end{array}$ & $\begin{array}{l}\text { Dose: } 48 \times 7 \times 20 \text { min } \\
\text { Length of session: } 20 \text { min } \\
\text { Frequency: Daily } \\
\text { Intensity: Not reported } \\
\text { Total duration: } 12 \text { months }\end{array}$ & $\begin{array}{l}\text { Angina symptoms } \\
\text { (CCS), exercise capacity, } \\
\text { revascularisations, MI, } \\
\text { cost- effectiveness, } \\
\text { combined clinical } \\
\text { endpoint (death } \\
\text { cardiac, stroke, CABG, } \\
\text { PCl, AMl, worsening } \\
\text { angina with objective } \\
\text { evidence resulting in } \\
\text { hospitalisation) }\end{array}$ & 12 months & $\begin{array}{l}\text { Germany, single } \\
\text { centre }\end{array}$ \\
\hline $\begin{array}{l}\text { Jiang et al } \\
2007\end{array}$ & $\begin{array}{l}167 \text { first } \\
\text { hospitalised with } \\
\text { angina pectoris } \\
\text { or Ml; } \\
71.2 \% \text { men }\end{array}$ & $\begin{array}{l}\text { Hospital-based } \\
\text { patient/family } \\
\text { education and } \\
\text { home-based } \\
\text { rehabilitation care }\end{array}$ & $\begin{array}{l}\text { Dose: Not reported } \\
\text { Length of session: Not reported } \\
\text { Frequency: Not reported } \\
\text { Intensity: Not reported } \\
\text { Total duration: } 12 \text { weeks }\end{array}$ & $\begin{array}{l}\text { None relevant to this } \\
\text { review }\end{array}$ & 6 months & China, single centre \\
\hline $\begin{array}{l}\text { Manchanda et } \\
\text { al } 2000^{22}\end{array}$ & $\begin{array}{l}42 \text { chronic stable } \\
\text { angina pectoris } \\
\text { and coronary } \\
\text { artery disease } \\
\text { (CAD); } 100 \% \text { men }\end{array}$ & $\begin{array}{l}\text { Home-based } \\
\text { yoga lifestyle } \\
\text { intervention } \\
\text { programme }\end{array}$ & $\begin{array}{l}\text { Dose: } 48 \times 7 \times 90 \text { min } \\
\text { Length of session: } 90 \text { min } \\
\text { Frequency: Daily } \\
\text { Intensity: Moderate } \\
\text { Total duration: } 12 \text { months }\end{array}$ & $\begin{array}{l}\text { All-cause mortality, } \\
\text { severity of angina, } \\
\text { revascularisation, } \\
\text { exercise capacity }\end{array}$ & 12 months & India, single centre \\
\hline $\begin{array}{l}\text { Schuler et al } \\
1992^{20}\end{array}$ & $\begin{array}{l}113 \text { stable angina } \\
\text { pectoris; } 100 \% \\
\text { men }\end{array}$ & $\begin{array}{l}\text { Home-based } \\
\text { aerobic training } \\
\text { (bicycle ergometer) }\end{array}$ & $\begin{array}{l}\text { Dose: } 48 \times 7 \times 30 \text { min (daily exercise) } \\
\text { plus } 48 \times 2 \times 60 \text { min (weekly exercise) } \\
\text { Length of session: } 30 \text { min minimum } \\
\text { Frequency: Daily } \\
\text { Intensity: } 75 \% \text { maximal heart rate } \\
\text { during symptom-limited exercise } \\
\text { Total duration: } 12 \text { months }\end{array}$ & $\begin{array}{l}\text { All-cause mortality, } \\
\text { MI, revascularisations, } \\
\text { exercise capacity, } \\
\text { adverse events }\end{array}$ & 12 months & $\begin{array}{l}\text { Germany, single } \\
\text { centre }\end{array}$ \\
\hline $\begin{array}{l}\text { Todd et al } \\
1991^{19}\end{array}$ & $\begin{array}{l}40 \text { chronic } \\
\text { stable angina }>6 \\
\text { months duration }\end{array}$ & $\begin{array}{l}\text { Home-based } \\
\text { aerobic training } \\
\text { (Canadian Air Force } \\
\text { Programme) }\end{array}$ & $\begin{array}{l}\text { Dose: } 48 \times 7 \times 11 \\
\text { Length of session: } 11 \mathrm{~min} \\
\text { Frequency: Daily } \\
\text { Intensity: Increasing intensity with no } \\
\text { limit on maximum exercise level } \\
\text { Total duration: } 12 \text { months }\end{array}$ & $\begin{array}{l}\text { All-cause mortality, MI, } \\
\text { exercise capacity }\end{array}$ & 12 months & UK, single centre \\
\hline
\end{tabular}

AMI, acute myocardial infarction; CABG, coronary artery bypass graft; CCS, Canadian Cardiovascular Society; HRQoL, health-related quality of life; MI, myocardial infarction; $\mathrm{PCl}$, percutaneous coronary intervention.

pooled RR for risk of MI of 0.33 (95\% CI: 0.07 to 1.63, $\mathrm{I}^{2}=0 \%$, fixed effects). We are uncertain if CR has little or no effect on the incidence of MI due to very low-quality evidence (Summary of findings table 3 ).

Three studies ${ }^{20-22}$ (256 participants) reported on the incidence of revascularisations with a total of 28 events. In total, six revascularisations were reported among the
CR groups in the three studies, and 22 in the control groups, with a pooled RR for risk of revascularisations of 0.27 (95\% CI: 0.11 to $0.64, \mathrm{I}^{2}=0 \%$, fixed effects). We are uncertain if CR has little or no effect on the incidence of revascularisations due to very low-quality evidence (Summary of findings table 3). 
Table 2 Summary of study characteristics

Number of studies (\%) or median (range)

\begin{tabular}{|c|c|}
\hline \multicolumn{2}{|l|}{ Study characteristics } \\
\hline \multicolumn{2}{|l|}{ Publication year } \\
\hline 1980-1999 & 3 \\
\hline 2000-2009 & 3 \\
\hline 2010 onwards & 1 \\
\hline \multicolumn{2}{|l|}{ Study location } \\
\hline Europe & 5 \\
\hline Australasia & 2 \\
\hline Single centre & 7 \\
\hline Sample size & $126(24-167)$ \\
\hline Duration of follow-up & 9.4 months $(6-12)$ \\
\hline \multicolumn{2}{|l|}{ Comparator } \\
\hline Usual medical care & 6 \\
\hline $\mathrm{PCl}$ & 1 \\
\hline \multicolumn{2}{|l|}{ Population characteristics } \\
\hline \multicolumn{2}{|l|}{ Sex } \\
\hline Males only & 4 \\
\hline Both males and females & 3 \\
\hline Age (years) & $56.6(50-66.2)$ \\
\hline \multicolumn{2}{|l|}{ Intervention characteristics } \\
\hline \multicolumn{2}{|l|}{ Intervention type } \\
\hline Exercise-only programme & 4 \\
\hline Comprehensive programme & 3 \\
\hline Duration of intervention (months) & $57.5(1.5-12)$ \\
\hline \multicolumn{2}{|l|}{ Nature of intervention } \\
\hline Aerobic only & 7 \\
\hline Aerobic and resistance & 0 \\
\hline \multicolumn{2}{|l|}{ Dose of intervention } \\
\hline Duration & 57.5 months (1.5-12) \\
\hline Frequency & 1-7 sessions/week \\
\hline Length & 11-90 min/session \\
\hline Intensity & $\begin{array}{l}\text { 70\%-75\% of maximal heart } \\
\text { rate } \\
\text { - 'Moderate' intensity }\end{array}$ \\
\hline \multicolumn{2}{|l|}{ Setting } \\
\hline Centre-based only & 1 \\
\hline $\begin{array}{l}\text { Combination of centre- and } \\
\text { home-based }\end{array}$ & 3 \\
\hline Home-based only & 2 \\
\hline
\end{tabular}

$\mathrm{PCl}$, percutaneous coronary intervention.

One study ${ }^{21}$ (101 participants) reported that one CR participant and seven control participants experienced cardiovascular-related hospital admissions (RR 0.14, 95\% CI: 0.02 to 1.10 ). We are uncertain if CR has little or no effect on the incidence of cardiovascular-related hospital

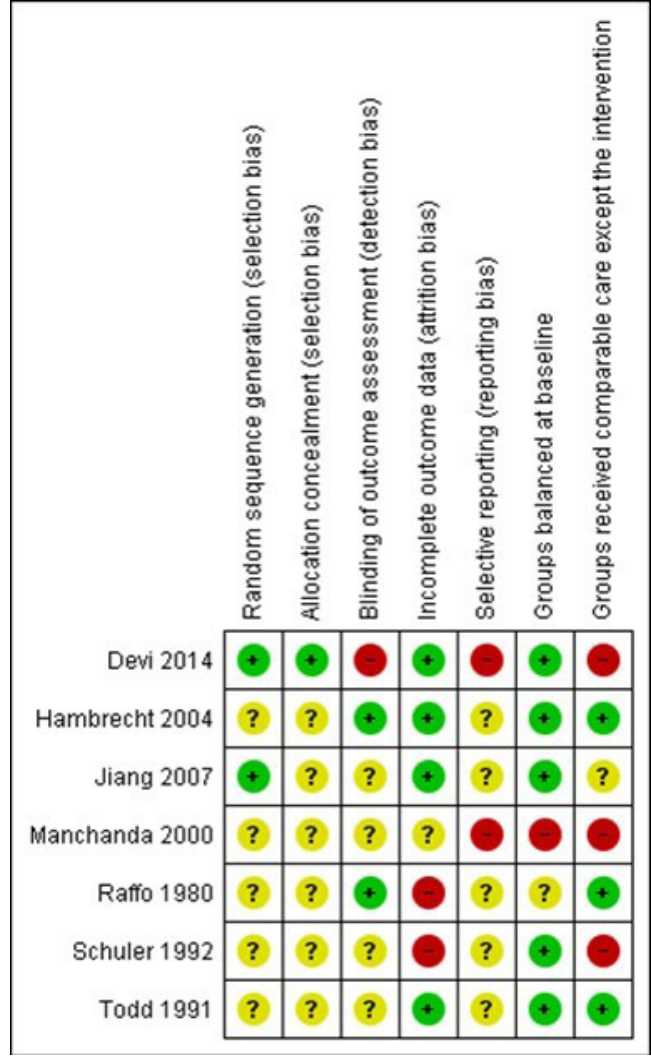

Figure 2 Risk of bias summary: review authors' judgements about each risk of bias item for each included study. + (green), low risk of bias; ? (yellow), unclear risk of bias; (red), high risk of bias.

admissions due to very low-quality evidence (Summary of findings table 3). None of the included studies reported all-cause hospital admissions.

\section{Exercise capacity}

Five studies ${ }^{18-22}$ (267 participants) reported exercise capacity with a range of validated measures (peak oxygen uptake and exercise duration) (figure 3). CR may result in a moderate improvement in exercise capacity with $\mathrm{CR}$ compared with control in the short term (6-12 months follow-up) (SMD 0.45, 95\% CI: 0.20 to $0.70 ; \mathrm{I}^{2}=16 \%$, fixed effects) (figure 3) based on low-quality evidence (Summary of findings table 3). Studies varied in degree of losses to follow-up which ranged from $0 \%^{20}$ to $29 \%^{21}$ in the intervention arm.

HRQoL

One study ${ }^{23}$ (94 participants) reported HRQoL using validated disease-specific instruments (Seattle angina questionnaire and MacNew questionnaire). Compared with control, improvements with $\mathrm{CR}$ at the 6-week follow-up were seen in emotional score $(p=0$.04) and angina frequency $(p=0.002)$. Benefits in favour of CR in angina frequency $(\mathrm{P}=0.02)$ and social HRQoL score $(\mathrm{p}=0.02)$ were also observed at the 6 -month follow-up. We are uncertain of the effect of CR on HRQoL due to very low-quality evidence (Summary of findings table 3). 
Table 3 Summary of findings table

\section{Anticipated absolute effects ${ }^{\star}$}

$(95 \% \mathrm{Cl})$

\begin{tabular}{|c|c|c|c|c|c|}
\hline Outcomes & $\begin{array}{l}\text { Risk with usual } \\
\text { care }\end{array}$ & $\begin{array}{l}\text { Risk with } \\
\text { exercise-based } \\
\text { CR }\end{array}$ & $\begin{array}{l}\text { Relative effect } \\
(95 \% \mathrm{Cl})\end{array}$ & $\begin{array}{l}\text { No of participants } \\
\text { (studies) }\end{array}$ & $\begin{array}{l}\text { Quality of the } \\
\text { evidence } \\
\text { (GRADE) }\end{array}$ \\
\hline $\begin{array}{l}\text { All-cause mortality } \\
\text { Follow-up: } 12 \text { months }\end{array}$ & 20 per 1000 & $\begin{array}{l}21 \text { per } 1000 \\
(4 \text { to } 116)\end{array}$ & $\begin{array}{l}\text { RR } 1.01 \\
\text { (0.18 to } 5.67)\end{array}$ & $\begin{array}{l}195 \\
\text { (3 RCTs) }\end{array}$ & $\begin{array}{l}\oplus \bigcirc \bigcirc \bigcirc \\
\text { Very low*t‡ }\end{array}$ \\
\hline $\begin{array}{l}\text { AMl } \\
\text { Follow-up: } 12 \text { months }\end{array}$ & 39 per 1000 & $\begin{array}{l}13 \text { per } 1000 \\
\text { (3 to } 64)\end{array}$ & $\begin{array}{l}\text { RR } 0.33 \\
(0.07 \text { to } 1.63)\end{array}$ & $\begin{array}{l}254 \\
(3 \mathrm{RCTs})\end{array}$ & 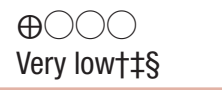 \\
\hline $\begin{array}{l}\text { Exercise capacity assessed } \\
\text { using a variety of outcomes } \\
\text { including } \mathrm{VO}_{2} \text { max and duration } \\
\text { of exercise } \\
\text { Follow-up: range } 6 \text { months to } \\
12 \text { months }\end{array}$ & \multicolumn{2}{|c|}{$\begin{array}{l}\text { The mean exercise capacity in the } \\
\text { intervention groups was } 0.45 \mathrm{SD} \text { higher( } 0.2\end{array}$} & - & $\begin{array}{l}267 \\
(5 \mathrm{RCTs})\end{array}$ & $\begin{array}{l}\oplus \oplus \bigcirc \bigcirc \\
\text { Low }^{* *}\end{array}$ \\
\hline $\begin{array}{l}\text { Cardiovascular hospital } \\
\text { admissions assessed with: } \\
\text { Combined clinical endpoint } \\
\text { (cardiac death, stroke, CABG, } \\
\text { PCI, AMl, worsening angina } \\
\text { with objective evidence } \\
\text { resulting in hospitalisation) } \\
\text { Follow-up: } 12 \text { months }\end{array}$ & \multicolumn{2}{|c|}{$\begin{array}{l}\text { Risk with usual care } 140 \text { per } 1000 \\
\text { Risk with exercise-based CR } 20 \text { per } 1000 \\
(2-154)\end{array}$} & $\begin{array}{l}\text { RR } 0.14 \\
(0.02 \text { to } 1.1)\end{array}$ & $\begin{array}{l}101 \\
(1 \mathrm{RCT})\end{array}$ & $\begin{array}{l}\oplus \bigcirc \bigcirc \bigcirc \\
\text { Very lowtt†ł‡ }\end{array}$ \\
\hline $\begin{array}{l}\text { HRQoL assessed with: Seattle } \\
\text { angina questionnaire and The } \\
\text { MacNew questionnaire } \\
\text { Follow-up: range } 6 \text { weeks to } 6 \\
\text { months }\end{array}$ & \multicolumn{2}{|c|}{$\begin{array}{l}\text { One study showed improvement in } \\
\text { emotional score at } 6 \text { week follow-up, and } \\
\text { benefits in angina frequency and social } \\
\text { HRQoL score at } 6 \text { months follow-up }\end{array}$} & Not estimable & $\begin{array}{l}94 \\
(1 \mathrm{RCT})\end{array}$ & $\begin{array}{l}\oplus \bigcirc \bigcirc \bigcirc \\
\text { VERY LOW§§ł‡ }\end{array}$ \\
\hline Return to work & \multicolumn{2}{|c|}{$\begin{array}{l}\text { No studies were found that looked at return } \\
\text { to work. }\end{array}$} & - & - & - \\
\hline $\begin{array}{l}\text { Adverse events } \\
\text { Follow-up: } 12 \text { months } \\
\text { For example, skeletomuscular } \\
\text { injury }\end{array}$ & \multicolumn{2}{|c|}{$\begin{array}{l}\text { Only one study looked at adverse events } \\
\text { and reported that there were no adverse } \\
\text { events during the exercise-based CR. }\end{array}$} & Not estimable & $\begin{array}{l}101 \\
(1 \mathrm{RCTs})\end{array}$ & $\begin{array}{l}\oplus \bigcirc 0 \bigcirc \\
\text { Very low t+ttł }\end{array}$ \\
\hline
\end{tabular}

* The risk in the intervention group (and its $95 \%$ confidence interval) is based on the assumed risk in the comparison group and the relative effect of the intervention (and its $95 \% \mathrm{Cl}$ )

*Some concerns with random sequence generation, allocation concealment, blinding of outcome assessment and selective reporting; bias likely, therefore quality of evidence downgraded by one level.

†Some concern with applicability to review question as participants in all studies were limited to middle-aged men, therefore quality of evidence downgraded by one level.

†Imprecise due to small number of participants (less than 300) and Cls including potential for important harm or benefit as $95 \% \mathrm{Cl}$ crosses $\mathrm{RR}$ of 0.75 and 1.25 , therefore quality of evidence downgraded by two levels.

§Some concern with random sequence generation, allocation concealment, blinding of outcome assessment, high loss to follow-up, selective reporting and unbalanced groups at baseline; serious bias likely, therefore quality of evidence downgraded by two levels.

ๆSome concern with random sequence generation, allocation concealment, blinding of outcome assessment, selective reporting and unbalanced groups at baseline; bias likely, therefore quality of evidence downgraded by one level.

${ }^{* *}$ Imprecise due to small number of participants (less than 300), therefore quality of evidence downgraded by one level.

$\dagger \dagger$ Some concerns with random sequence generation, allocation concealment and selective reporting; bias likely, therefore quality of evidence downgraded by one level.

$\ddagger \ddagger$ Imprecise due to very small number of participants therefore quality of evidence downgraded by two levels.

$\S \S$ Some concerns with blinding of outcome assessment, selective reporting and groups not receiving comparable care; bias likely, therefore quality of evidence downgraded by one level.

AMI, acute myocardial infarction; CABG, coronary artery bypass graft; CR, cardiac rehabilitation; GRADE, Grading of Recommendations Assessment, Development and Evaluation; HRQoL, health-related quality of life; $\mathrm{PCl}$, percutaneous coronary intervention; RCT, randomised controlled trial.

\section{Severity of angina}

One study $^{22}$ (42 participants) reported a reduction in mean New York Heart Association (NYHA) score from baseline to 1-year follow-up (2.6-1.4, $\mathrm{p}<0.0001)$ with $\mathrm{CR}$ and an increase in mean NYHA in control (2.3-2.9, $\mathrm{p} \leq 0.004)$. Another study ${ }^{21}$ (101 participants) reported an 


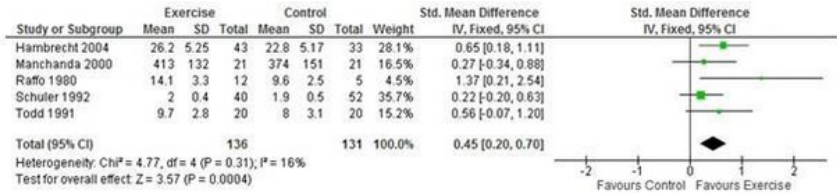

Figure 3 Exercise capacity with exercise-based CR versus no exercise for stable angina. CR, cardiac rehabilitation.

improvement in angina severity assessed by mean Canadian Cardiovascular Society score in both CR (1.5-0.4, $\mathrm{p}<0.001)$ and control $(1.7-0.7, \mathrm{p}<0.001)$. We assessed the evidence as very low-quality using GRADE because of concerns about risk of bias (random sequence generation, allocation concealment, blinding of outcome assessment, selective reporting, high losses to follow-up and unbalanced groups at baseline), concerns about applicability to review question (participants in all studies were limited to middle-aged men) and concerns about imprecision (small number of participants). Data could not be pooled in a meta-analysis because of scales used to report outcome measures (ie, NYHA is categorical while CCS is continuous).

\section{Adverse events}

Adverse events were only reported in one study ${ }^{21}$ (101 participants). The authors reported 'no adverse events' during the exercise training programme in the CR group (summary of findings in table 3).

\section{Healthcare costs}

One study $^{21}$ (101 participants) reported a difference in mean participant healthcare costs in favour of CR (CR: US\$3708 vs control: US\$6086, $\mathrm{p}<0.0001)$. These costs included hospitalisations, repeat vascularisations, any other cardiovascular events plus the costs of the provision of the CR exercise training programme. We assessed this evidence as very low-quality using GRADE because of concerns about risk of bias (random sequence generation, allocation concealment, high losses to follow-up and selective reporting), concerns about applicability to review question (participants in all studies were limited to middle-aged men) and concerns about imprecision (small number of participants). We are uncertain of the effect of CR on healthcare costs due to very low-quality evidence.

\section{Return to work}

None of the included studies reported on return to work (summary of findings in table 3)

\section{Small study bias}

There were insufficient ( $<10$ RCTs) studies to assess small study bias using Funnel plot or Egger test.

\section{DISCUSSION}

This systematic review identified seven RCTs in 581 patients with a confirmed diagnosis of stable angina that compared exercise-based CR with a no exercise control. Meta-analysis and GRADE analysis showed there may be an improvement in exercise capacity following CR compared with control in the short term (up to 12 months follow-up, low-quality evidence). However, there was insufficient evidence to be able to definitely assess impact of CR on mortality, morbidity, or HRQoL.

The limited evidence base for CR for stable angina identified by this review is in contrast to that reported for post-MI, following coronary revascularisation, and in patients with HF. A Cochrane meta-analysis of exercise-based CR for CHD identified 63 RCTs in 14486 patients, the majority following MI or coronary revascularisation. Compared with no-exercise control, the authors reported that $\mathrm{CR}$ reduced the risk of cardiovascular mortality (risk ratio (RR) $0.74,95 \%$ CI 0.64 to 0.86 and hospital admission (RR $0.82,95 \%$ CI 0.70 to 0.96 ) and improved HRQoL. ${ }^{11}$ A systematic review and meta-analysis comparing the effects of home-based and supervised centre-based CR found similar benefits in terms of clinical and HRQoL outcomes at equivalent cost for patients with $\mathrm{HF}$ and following MI and revascularisation. ${ }^{24}$ The precise mechanisms by which CR may improve mortality in people with CHD has not been fully elucidated. Exercise training has been shown to have direct benefits on the heart and coronary vasculature, including autonomic tone, endothelial function, myocardial oxygen demand, coagulation and clotting factors, inflammatory markers, and the development of coronary collateral vessels. ${ }^{25-27}$ However, it has been suggested that approximately half of the $28 \%$ reduction in cardiac mortality in people with CHD may also be mediated via the indirect effects of exercise through improvements in the risk factors for atherosclerotic disease (ie, smoking, blood pressure and total cholesterol). ${ }^{28}$

A recent review that focused on contemporary exercise-based CR found no improvement in all-cause mortality and potential benefit on hospital admissions. ${ }^{29}$

A recent Cochrane review from $2019^{30}$ of exercise-based CR identified 44 RCTs that included 5783 people with HF. The findings show important benefits of exercise-based rehabilitation that include a probable reduction in the risk of overall hospital admissions in the short term (RR: $0.7,95 \%$ CI 0.6 to 0.83 ), as well as the potential for reduction in HF admissions (RR: $0.5995 \%$ CI 0.42 to 0.84 ) compared with usual care control. The effect of exercise-based rehabilitation on HRQoL is uncertain due to very low-quality evidence. Exercise-based rehabilitation may make little or no difference in all-cause mortality in trials with follow-up less than 12 months.

\section{Strengths and limitations}

We believe this to be the first systematic review and meta-analysis to specifically assess the impact of CR in patients with stable angina. Strengths of this review include extensive literature searches, consideration of RCTs, application of Cochrane review methodology and consideration of a wide range of outcomes. However, a major limitation was the small number of RCTs and 
patients included in the studies. It was therefore not possible to assess potential small study effects and publication bias. Trials generally recruited primarily younger middle-aged men, ${ }^{19-22}$ limiting external generalisability. A number of the trials were in patient populations with poorly defined baseline characteristics in terms of their angiographic coronary disease and left ventricular ejection fraction and were not receiving contemporary medical therapy (ie, antiplatelet, antianginal and revascularisation therapies).

\section{Implications for clinical practice and future research}

It is estimated that stable angina is prevalent in over 1.3 million people in the $\mathrm{UK}^{4}$ and in approximately 112 million people, or $1.6 \%$ of the population worldwide. ${ }^{5}$ The findings of this review support NICE clinical guidance that there is currently insufficient evidence to conclude whether CR is clinically effective or cost-effective for stable angina.

Adequately powered, high-quality, multi-centre randomised trials of exercise-based CR in patients with stable angina receiving contemporary medical care are required. Such trials should seek to compare CR to contemporary usual care, assessing outcomes that include symptom burden with validated angina questionnaires and HRQoL measures, report clinical events including hospital admissions, all-cause mortality, and, costs and cost-effectiveness.

\section{CONCLUSIONS}

The results of this systematic review and meta-analysis show that exercise-based CR may improve short-term exercise capacity in patients with stable angina pectoris. There is insufficient evidence to draw conclusions for any other outcome. Given the limited body of available evidence, well-designed RCTs in a contemporary patient population are required to definitely assess the impact of adding CR to usual care in terms of mortality, morbidity, HRQoL and costs.

Acknowledgements The review authors thank the Cochrane Heart editorial team for their support. The review authors would also like to express their sincere thanks to Helen Wakefield and the Cochrane Fast-Track team.

Contributors LL contributed to writing the protocol, undertook the 'Risk of bias' assessment, conducted the GRADE analysis and led the writing of the final review manuscript. LA led writing of the protocol, undertook study selection and data extraction and contributed to writing the final review manuscript. $A D$ contributed to writing the protocol and manuscript, undertook study selection, data extraction and 'Risk of bias' assessment, and approved the final review manuscript. JH provided clinical expertise, assisted in writing the protocol, undertook study selection, data extraction and 'Risk of bias' assessment. MMG contributed to writing the protocol and provided clinical expertise. RST led the statistical analysis, conducted the GRADE analysis, edited the review and contributed to writing the final review manuscript. All authors approved the final review.

Funding Internal sources: University of Exeter Medical School. External sources: The Cochrane Heart Group US Satellite is supported by intramural support from the Northwestern University Feinberg School of Medicine and the Northwestern University Clinical and Translational Science (NUCATS) Institute (UL1TR000150), USA. This project was supported by the National Institute for Health Research, via Cochrane Incentive funding to the Heart Group. The views and opinions expressed therein are those of the authors and do not necessarily reflect those of the Systematic Reviews Programme, NIHR, NHS or the Department of Health, UK.

Competing interests LA is an author on a number of other Cochrane reviews on cardiac rehabilitation (CR). RST is an author on a number of other Cochrane reviews on $\mathrm{CR}$ and is currently the co-chief investigator on the programme of research with the overarching aims of developing and evaluating a home-based CR intervention for people with heart failure and their carers (NIHR PGfAR RP-PG-0611-12004).

Patient consent for publication Not required.

Provenance and peer review Not commissioned; externally peer reviewed.

Data availability statement Data are available in a public, open access repository. All data relevant to the study are included in the article or uploaded as supplementary information.

Open access This is an open access article distributed in accordance with the Creative Commons Attribution 4.0 Unported (CC BY 4.0) license, which permits others to copy, redistribute, remix, transform and build upon this work for any purpose, provided the original work is properly cited, a link to the licence is given, and indication of whether changes were made. See: https://creativecommons.org/ licenses/by/4.0/.

\section{REFERENCES}

1. Dalal HM, Doherty P, Taylor RS. Cardiac rehabilitation. BMJ 2015;351.

2. Scottish Intercollegiate Guidelines Network (SIGN)ISBN 189989392X. Cardiac rehabilitation. Edinburgh; 2002.

3. British Association for Cardiovascular Prevention and Rehabilitation. The BACPR standards and core components for cardiovascular disease prevention and rehabilitation. 2nd edition, 2016.

4. British Heart Foundation. Cardiovascular disease statistics 2014. British Heart Foundation Centre on Population Approaches for Non-Communicable Disease Prevention, Nuffield Department of Population Health, University of Oxford, 2014.

5. Vos T, Flaxman AD, Naghavi M, et al. Years lived with disability (YLDs) for 1160 sequelae of 289 diseases and injuries 1990-2010: a systematic analysis for the global burden of Disease Study 2010. Lancet 2012;380:2163-96.

6. Fihn SD, Gardin JM, Abrams J, et al. 2012 ACCF/AHA/ACP/AATS/ PCNA/SCAI/STS guideline for the diagnosis and management of patients with stable ischemic heart disease. J Am Coll Cardiol 2012;60:e44-164.

7. Montalescot G, Sechtem U, Achenbach S, et al. 2013 ESC guidelines on the management of stable coronary artery disease. Eur Heart J 2013;34:2949-3003.

8. National institute for Health and Clinical Excellence. CG126: stable angina (full guideline). Available: www.nice.org.uk/guidance/cg126/ evidence/full-guideline-183176605 [Accessed 11 July 2017].

9. Higgins JPT, Green S, eds. Cochrane Handbook for Systematic Reviews of Interventions Version 5.1.0. The Cochrane Collaboration, 2011.

10. Anderson L, Dewhirst AM, He J, et al. Exercise-based cardiac rehabilitation for patients with stable angina. Cochrane Database Syst Rev 2017;124.

11. Anderson L, Thompson DR, Oldridge N, et al. Exercise-based cardiac rehabilitation for coronary heart disease. Cochrane Database Syst Rev 2016;(1):CD001800.

12. Anderson L, Brown JP, Clark AM, et al. Patient education in the management of coronary heart disease. Cochrane Database Syst Rev 2017;6:CD008895.

13. Sibilitz KL, Berg SK, Tang LH, et al. Exercise-based cardiac rehabilitation for adults after heart valve surgery. Cochrane Database Syst Rev 2016;8.

14. Taylor RS, Sagar VA, Davies EJ, et al. Exercise-based rehabilitation for heart failure. Cochrane Database Syst Rev 2014;(4):CD003331.

15. Taylor RS, Dalal H, Jolly K, et al. Home-based versus centre-based cardiac rehabilitation. Cochrane Database Syst Rev 2010.

16. Egger M, Davey Smith G, Schneider M, et al. Bias in meta-analysis detected by a simple, graphical test. BMJ 1997;315:629-34.

17. Schünemann HJ, Oxman AD, Vist GE, et al. Chapter 12: Interpreting results and drawing conclusions. In: Higgins JPT, Green S, eds. Cochrane Handbook for systematic reviews of interventions version 5.1.0. The Cochrane Collaboration, 2011.

18. Raffo JA, Luksic IY, Kappagoda CT, et al. Effects of physical training on myocardial ischaemia in patients with coronary artery disease effects of physical training on myocardial ischaemia in patients with coronary artery disease. Br Heart J 1980;43:262-9. 
19. Todd IC, Bradnam MS, Cooke MB, et al. Effects of daily highintensity exercise on myocardial perfusion in angina pectoris. $\mathrm{Am} \mathrm{J}$ Cardiol 1991;68:1593-9.

20. Schuler G, Hambrecht R, Schlierf G, et al. Regular physical exercise and low-fat diet. Effects on progression of coronary artery disease. Circulation 1992;86:1-11.

21. Hambrecht $R$, Walther $C$, Möbius-Winkler $S$, et al. Percutaneous coronary angioplasty compared with exercise training in patients with stable coronary artery disease: a randomized trial. Circulation 2004; 109:1371-8

22. Manchanda SC, Narang R, Reddy KS, et al. Retardation of coronary atherosclerosis with yoga lifestyle intervention. J Assoc Physicians India 2000;48:687-94.

23. Devi R, Powell J, Singh S. A web-based program improves physical activity outcomes in a primary care angina population: randomized controlled trial. J Med Internet Res 2014;16:e186:1-12.

24. Buckingham SA, Taylor RS, Jolly K, et al. Home-based versus centre-based cardiac rehabilitation: abridged Cochrane systematic review and meta-analysis. Open Heart 2016;3:e000463.
25. Clausen JP, Trap-Jensen J. Heart rate and arterial blood pressure during exercise in patients with angina pectoris. Effects of training and of nitroglycerin. Circulation 1976;53:436-42.

26. Hambrecht R, Wolf A, Gielen S, et al. Effect of exercise on coronary endothelial function in patients with coronary artery disease. $N$ Engl $J$ Med 2000;342:454-60.

27. Lavie CJ, Arena R, Swift DL, et al. Exercise and the cardiovascular system: clinical science and cardiovascular outcomes. Circ Res 2015;117:207-19.

28. Powell R, McGregor G, Ennis S, et al. Is exercise-based cardiac rehabilitation effective? A systematic review and meta-analysis to re-examine the evidence. BMJ Open 2018;8:e019656.

29. Taylor RS, Unal B, Critchley JA, et al. Mortality reductions in patients receiving exercise-based cardiac rehabilitation: how much can be attributed to cardiovascular risk factor improvements? Eur $J$ Cardiovasc Prev Rehabil 2006;13:369-74.

30. Long L, Mordi IR, Bridges C, et al. Exercise-based cardiac rehabilitation for adults with heart failure. Cochrane Database Syst Rev 2019;8. 